\title{
EURASIAN JOURNAL OF SOCIAL SCIENCES http://www.eurasianpublications.com/
}

\section{Problems of a Modern Spatial Organization in the Euro-Asia REGION}

\author{
Julia Lavrikova \\ The Institute of Economics of the Ural Branch of RAS, Russia. Email: k515I@mail.ru
}

Svetlana Kotlyarova

The Institute of Economics of the Ural Branch of RAS, Russia. Email: sv_gavrilova@mail.ru

\section{Arina Suvorova}

Corresponding Author: The Institute of Economics of the Ural Branch of RAS, Russia.

Email: gotika.bell@mail.ru

\begin{abstract}
The objective of this paper is to describe the trend of modern processes of transformation in the spatial organization of the Euro-Asian region. The study revealed several negative trends, which indicate the violation of the integrity of the spatial framework of the Euro-Asia region (that confirmed by the statistical data of some of the countries-Russia, Kazakhstan and Belarus). It is allowed to offer some of the activities that contribute to increasing connectedness of the space and reducing its disintegration.
\end{abstract}

Keywords: Spatial Organization, Economic Space, the Euro-Asia Region, Development of Territorial Systems

\section{Introduction}

In the context of increased competition between the participants of economic relations at all levels of the organization of economic activity all countries need to strengthen their position in the world economic community. This is not possible without the rational organization of economic activity (Lavrikova, 2008). And spatial aspects of management are particularly important for countries that have a considerable size and diversity of options of activities in different parts. Characteristics of economic space, its scale, particular qualities always determined and will determine the political, national, demographic, social and economic peculiarity of the Euro-Asian region. Strengthening relations between the countries of the EuroAsia region, their inclusion in the integration process is impossible in the conditions of heterogeneity of economic space of the territory.

\section{Key Problems of a Spatial Organization in Euro-Asia Region}

There are some of negative trends, which indicate the violation of the integrity of the spatial framework of the Euro-Asia region. 
We can observe obvious process of narrowing the economic space. Especially it can be seen in Russia. This is evident not only in reducing the population (Figure 1): from 2000 to 2014 population in the country decreased by 3.2 million people; but also in a sharp decrease in the number of settlements in the Russian Federation (according to the National Population Census 2002 and 2010, the total number of localities (cities, towns, etc.) decreased from 158,229 to 155,511 , i.e. by 2718). The result of this process is not only to reduce the territorial basis of the economy, but also a change in its spatial structure (Lejzerovich, 1995): the appearance of "voids" in the economic framework of the countries weakens subjects nearby, increases the load on other elements of the frame.

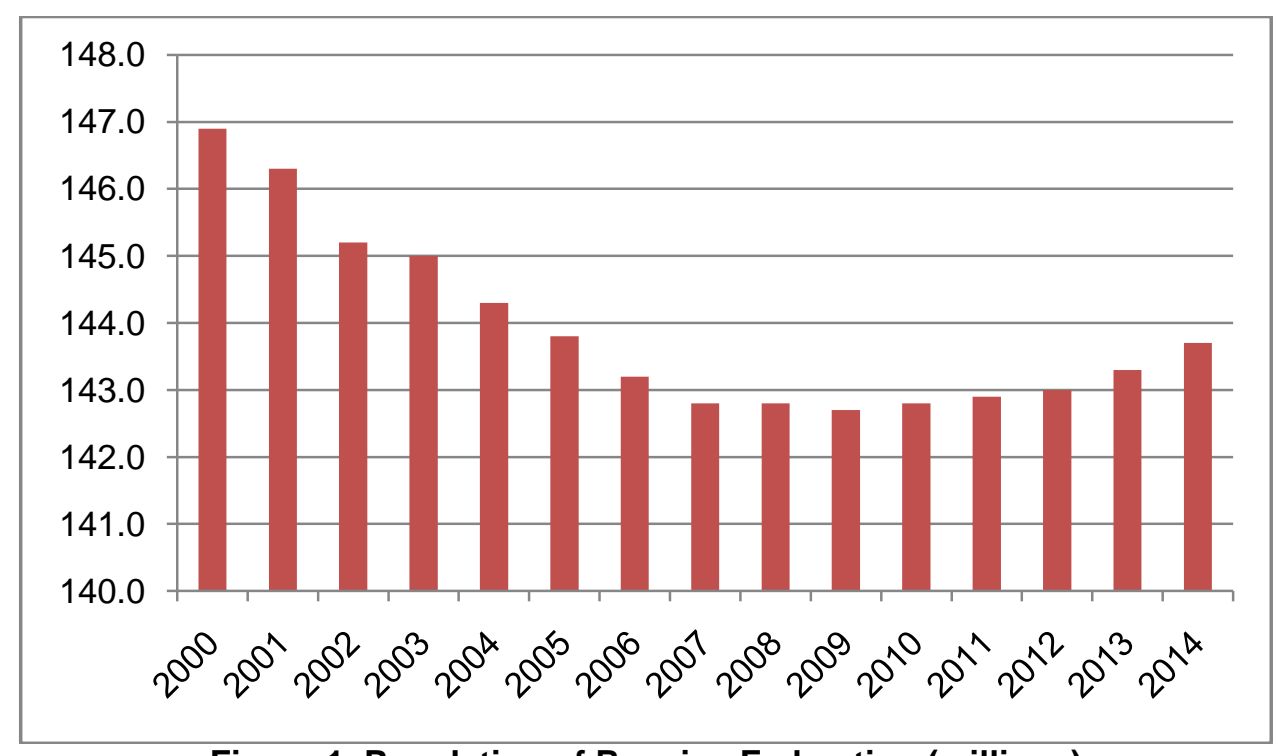

Figure 1. Population of Russian Federation (millions) Source: Federal State Statistic Service

The level of centralization of economic space is growing. Economic growth is increasingly concentrated in cities and major towns. For example, almost a quarter of the population of Russia (22\%) lives in 18 large and major cities-12 cities of over one million and 6 big cities (Perm, Voronezh, Krasnoyarsk, Saratov, Krasnoyarsk and Tolyatti). Centralizing tendencies particularly characteristic of Moscow (Figure 2), in particular in 2001 Moscow accounts for $15.3 \%$ of GDP, in $2013-17.6 \%$. 


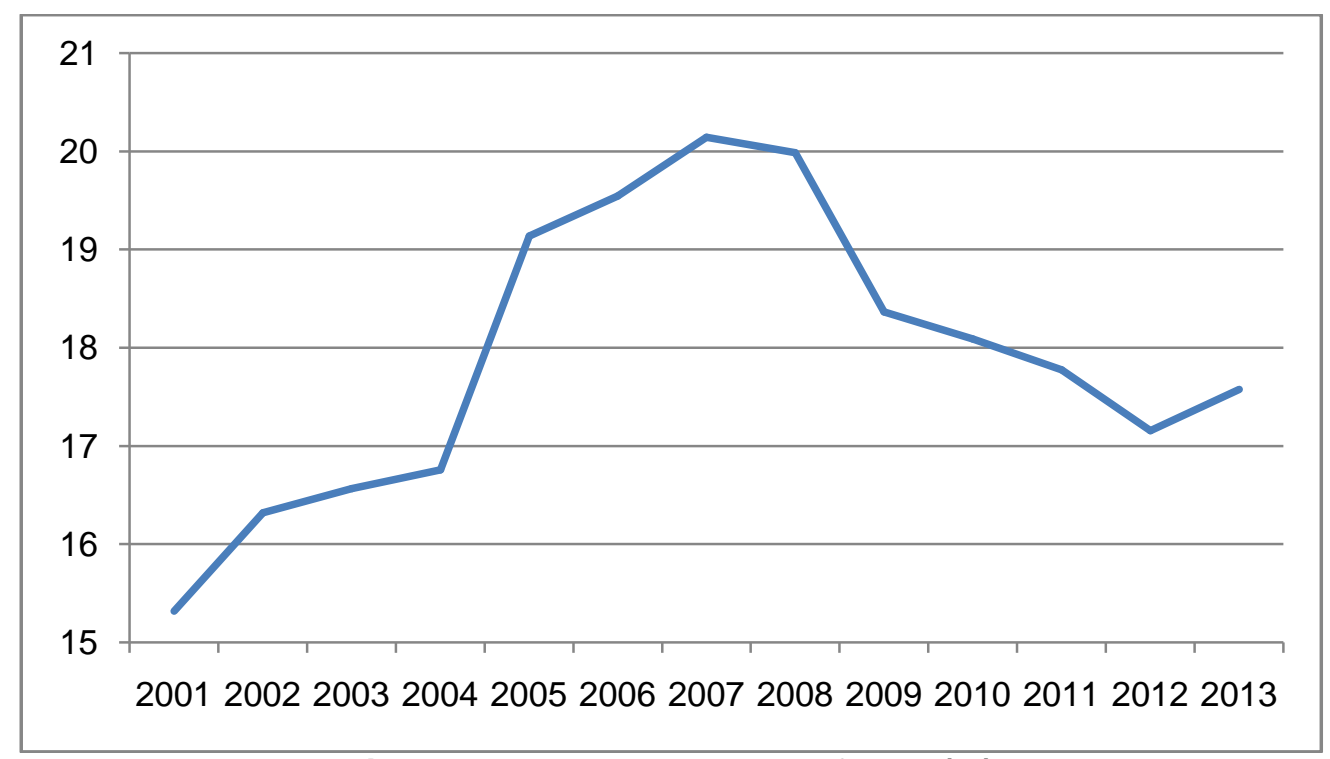

Figure 2. Moscow Accounts of GDP (\%)

Source: Federal State Statistic Service

Similar processes occur in other countries in the region. 31\% Kazakhstan's population lives in the three largest cities: Almaty, Astana and Shymkent (Figure 3). In the capital of Belarus (Minsk) $20.4 \%$ of the population of the whole country live (Figure 4).

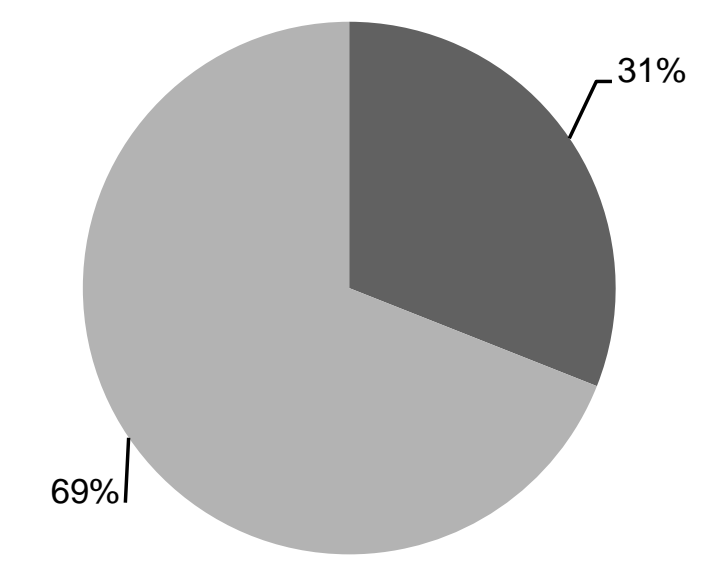

- Population of Almaty, Astana, Shymkent $\quad$ Population of other localities

Figure 3. Distribution of the Population in Kazakhstan (\%)

Source: Ministry of National Economy of the Republic of Kazakhstan 


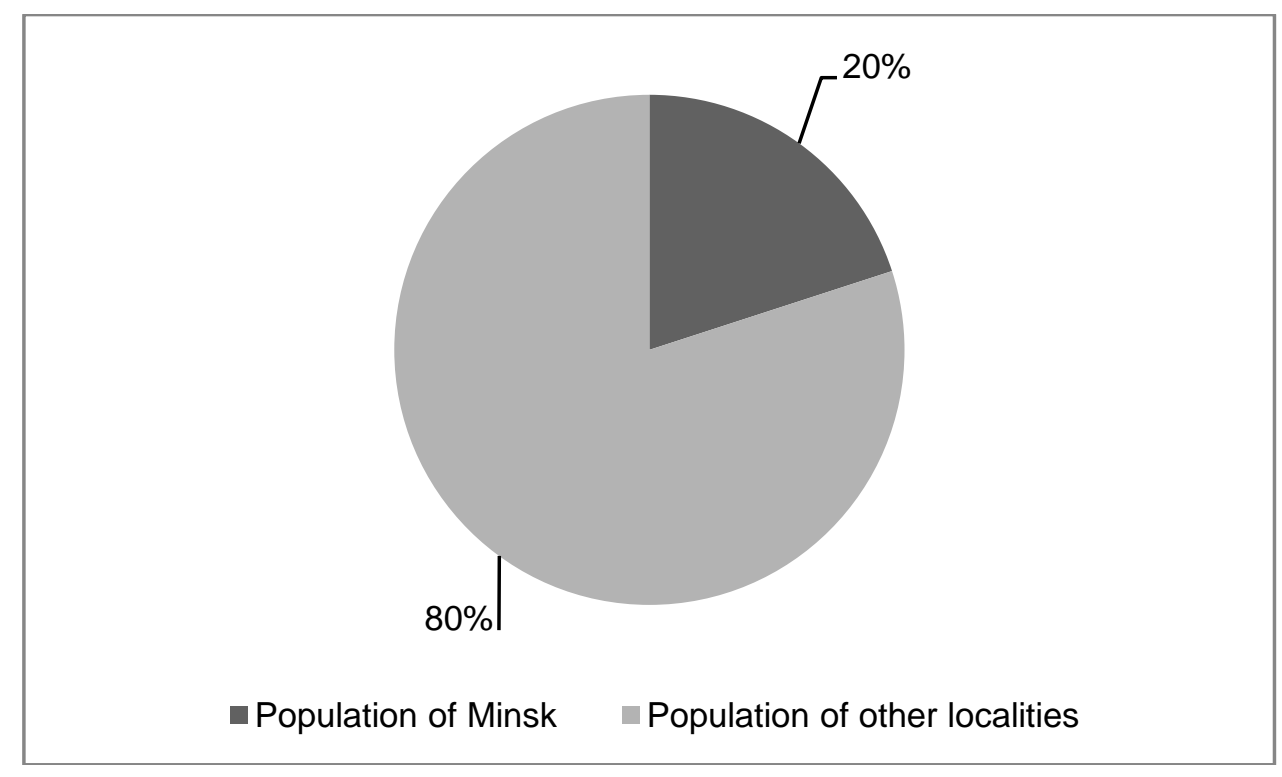

Figure 4. Distribution of the Population in Belarus (\%)

Source: National Statistic Committee of the Republic of Belarus

The concentration of a substantial portion of the assets in the one point in space reduces the overall efficiency of the economy due to irrational distribution and inability to control a large socio-economic system from one central location, complication of the population flows, goods, financial and other resources to one center and therefore the presence of the highest transaction costs.

Changing the load on the parts of spatial frame of the region increases the fragmentation of economic space (Animitsa, 2010). It is expressed in the growing differentiation of some countries on economic indicators. For example, in Russia there is a high difference between the economic development of certain parts of the country. So, from 2000 to 2013, the difference between the "extreme" regions on such indicators as gross regional product per capita increased from 26.5 to 28.7 times (Figure 5). 


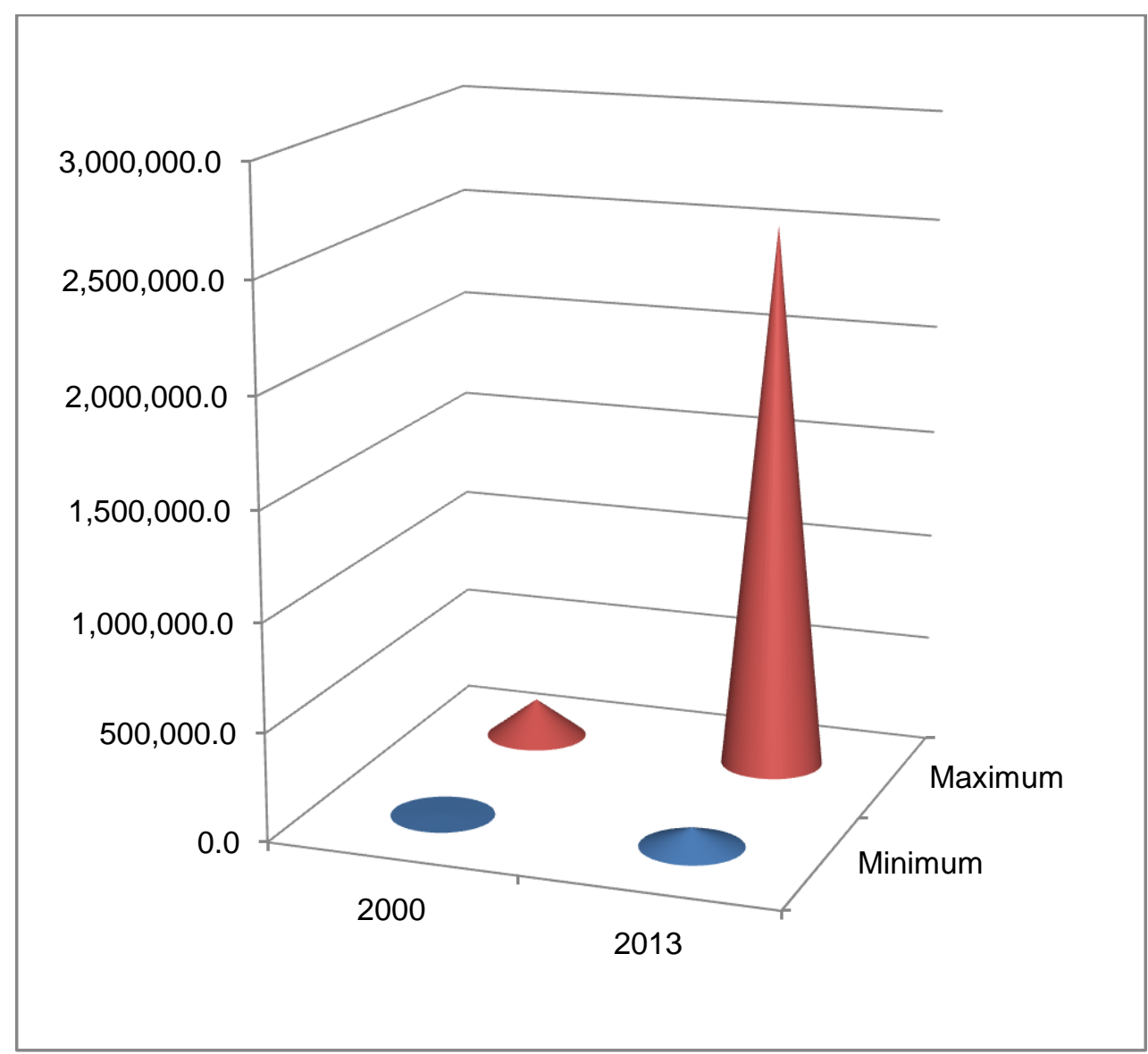

\section{Figure 5. The Difference between the "Extreme" Regions on Gross Regional Product per capita (Rubles) \\ Source: Federal State Statistic Service}

This territorial fragmentation suggests a lack of integrity of the economic space of the country, and regional disparities, in turn, are an important cause of its distortion.

Meanwhile, only on condition of formation and further strengthening of a common space of possible effective interaction of all participants in business processes: a strong and mutually beneficial relationship between the leaders and outsiders of economic development, whose characteristics differ by tens of times, impossible. countries.

No consistency in the management of spatial development of the economies of some

Optimization of the spatial structure of the economy is not one of the priorities pursued in countries of the Euro-Asian region policy: the space component of the majority of strategic documents is largely formal and "residual". There are no strategic and program documents of countries that would systematically regulate the spatial development of the territory (for example, the General scheme of development and placement of productive forces). Also established in some countries inter-territorial relations do not promote proactive development of individual regions and municipalities, and implemented activities focused on the transformation of the spatial organization of economic activity, are fragmented and inconsistent.

Thus, the spatial factor is not a competitive advantage for the region, for economic growth, social and economic development and modernization of society. The economic space in the region is very heterogeneously, the spatial structure of the economy is distorted, and carried out in the current policy is not focused on the optimization of the spatial characteristics (Buhvald, 2010). Meanwhile, ignoring the problem of imbalance of the spatial development of the economy can only lead to the deterioration of the situation: the further destruction of the 
space frame, the loss of a number of its segments, which will eventually lead to a violation of the integrity of the social and economic systems and reduce the competitiveness of the economic system of the region (Beketov, 2006).

\section{Ways to Solve the Problems of Spatial Organization in Euro-Asia Region}

It is important to transform the existing spatial organization of economic activities aimed at increasing connectedness of the space, reducing its disintegration and change its characteristics in accordance with modern requirements (Granberg, 1999; Minakir and Demjanenko, 2010). Experience shows that attempts to align the levels of economic development of the regions even with massive expenditure do not provide sustainable spatial development (Afoncev and Zubarevich, 2012). Irregularity is an objective property of spatial development. Overcoming spatial heterogeneity should not be interpreted as a desire for the absolute, "smoothing" characteristics of different regions, countries and the formation of a fully homogeneous economic area. This process is very difficult to implement, and the effectiveness of the activity of identical territorial complexes is small (absence of centers of economic growth may slow down the pace of development of individual regions and countries). Therefore, under the alignment of economic development of the territories it is advisable to understand the elimination of serious distortions of development, support lagging territories.

Thus, the spatial transformation should be directed to the formation of centers of development (centers of economic growth), and the reduction of inter-regional fragmentation. Despite the seeming inconsistency of these activities can be successfully combined with each other (but only if none of them not be reduced to the absolute predominance over the other "extreme condition" of any of these processes not only provide a dynamic and systematic development of the territory but rather hinder it). Moreover, it is a one-time implementation of these activities can help to achieve the desired results - the formation of a developed network of centers of economic growth of different levels will allow them generate and transmit pulses innovation development of economy to neighboring subjects with high degree of efficiency.

In each case, the question of the relationship between these two activities should be decided on the basis of evaluation of characteristics of the region (its state, development trends, changes in orientation). In this regard, it is important to note the importance of a differentiated approach to the definition of priority spatial transformation (we cannot develop a unified mechanism for the development of the territory).

At the same time, we must develop a common integrated and systematic approach to managing economic space, based on the use of market institutions and the current development trends.

This approach involves:

a. Creation a polycentric spatial structure of the economy by creating a favorable institutional environment through the progressive development of institutions and norms (Tatarkin, 2012). This means creation of multi-level centers of economic growth which actively interact and transmit arising multiplier effect, spreading the development impulse. This process should be based on informed choice of the potential (potential) centers of growth of the number of existing territorial units (or determine the location of the newly created centers of growth), which involves the development of methods (technologies) exercise of such choice - must consider the current situation, which characterizes the region (municipality), current trends, the position of the subject in the territorial structure of the country.

b. Formation technology development zones within the boundaries of the region and/or municipalities as one of the real institutions of self-development of territory. Typical examples of such areas that have received the approbation in the world are technology parks, science parks, innovation centers etc.

c. Creation, implementation and improvement of various types of development institutions, which should contribute to the innovation development of economic subjects, their integration, activation of all forms of support from the authorities. These institutions should be sufficiently diverse and provide a multi-purpose orientation of territorial development. The first group of institutions may be related to direct actions of the authorities to implement the main provisions of regional policy, especially with regard to problem areas (for example special 
funds). The second group includes institutions for the promotion of innovation development areas: technology parks, science parks and others. The third group of institutions can be oriented to change (introduction, improvement) technology of regional planning and management (the development of project management, indicative planning). The fourth group of institutions associated with the activation of the business community (in the form of strengthening horizontal linkages) through the development of clusters form, project planning and other.

d. Promotion self-development processes of territorial socio-economic systems (which contemplates the realization of the principles of self-organization, self-sufficiency and selfgovernment). Such systems should be self-sufficient (to have all the necessary resources development, characterized by the presence of objectives of activity and flexibility) and should be able to use a favorable external environment. Therefore, it is necessary, focusing on the system of common priorities of spatial development, use of socio-economic advantages of the territories, encouraging and motivating their initiative to compete with each other to attract resources for development.

e. Formation human-oriented paradigm of institutional development as basis of the reforms. The most important imperative of positive transformation of any system now is the development of human potential (Leksin, 1997) in particular its innovative components that determines the importance of the balanced social and personnel policy (this involves consideration of the territorial specificity of the development of a set of measures).

f. Using the principles of project management in organization of development of territorial systems. Application of methods of project management allows for more reasonably define the objectives and optimally plan various activities territories and countries, considering the specifics of the individual components of the spatial framework. Project management provides the ability to consider the risks, optimize the use of available resources and avoid conflicts, monitor the implementation of the plan, analyze the situation and correction activities in the course of work, save and use in the future experience of successful projects.

\section{Conclusion}

Strengthening relations between the countries of the Euro-Asia region, their inclusion in the integration process is impossible in the conditions of heterogeneity of economic space of the territory.

Meanwhile, there are some of negative trends, which indicate the violation of the integrity of the spatial framework of the Euro-Asia region. We can observe obvious process of narrowing the economic space (its result - reducing the territorial basis of the economy and the distortion of its spatial structure). The level of centralization of economic space is growing (economic growth concentrates in large cities). Changing the load on the parts of spatial frame of the region that increases the fragmentation of economic space (it is expressed in the growing differentiation of some countries on economic indicators). No consistency in the management of spatial development of the economies of some countries.

So it is important to change the current spatial organization of economic activity, focusing on increasing connectedness of the space and reducing its disintegration. This can be facilitated:

- creation of multi-level centres of economic growth which actively interact and transmit arising multiplier effect, spreading the development impulse;

- formation technology development zones (technology parks, science parks, innovation centers etc.)

- creation and improvement of various types of development institutions, which should contribute to the innovation development of economic subjects;

- promotion self-development processes of territorial socio-economic systems;

- human development (in particular its innovative components) through the implementation of a balanced social and personnel policy;

- using the principles of project management in organization of development of territorial systems. 


\section{References}

Afoncev, S. and Zubarevich, N., 2012. Spatial development as a mechanism for the modernization of the Republic of Kazakhstan. Problems of Economics, 5, pp.53-58.

Animitsa, E.G., 2010. Regional management. Ekaterinburg: The Ural State University of Economic.

Beketov, N.V., 2006. Modern problems of spatial organization of the economy of the Republic of Sakha (Yakutia). Regional Economy: Theory and Practice, 11, pp.20-28.

Buhvald, E.M., 2010. Spatial factors shaping the innovation economy in Russia. Federalism, 2, pp.55-68.

Federal State Statistic Service, 2014. Accounts. [online] Available at: $<\mathrm{http}: / / \mathrm{gks} . \mathrm{ru} / \mathrm{wps} / \mathrm{wcm} / \mathrm{connect/rosstat \_ main/rosstat/ru/statistics/accounts/ \# >}$ [Accessed 20 May 2015].

Federal State Statistic Service, 2015. Population. [online] Available at: $<\mathrm{http}: / / \mathrm{gks} . \mathrm{ru} / \mathrm{wps} / \mathrm{wcm} /$ connect/rosstat_main/rosstat/ru/statistics/population/demograph y/\#> [Accessed 20 May 2015].

Granberg, A., 1999. Economic space of Russia: Transformation at the turn of the century, and alternatives of the future. Society and Economy, 3-4, pp.225-244.

Lavrikova, J.G., 2008. Conceptual basis of spatial development of the regions. Journal of Economic Theory, 4, pp.147-162.

Lejzerovich, E.E., 1995. Levels of organization of the space: the economic and geographical analysis. Proceedings of the Russian Academy of Sciences. Geography Series, 2, pp.67-75.

Leksin, V.N. and Shvecov, A.N., 1997. The state and the regions: Theory and practice of state regulation of territorial development. Moscow: Librokom.

Minakir, P.A. and Demjanenko, A.N., 2010. The spatial economy: Evolution of approaches and methodology. Spatial Economics, 2, pp.6-32.

Ministry of National Economy of the Republic of Kazakhstan, 2015. Committee on Statistics. [online] Available at: <http://www.stat.gov.kz> [Accessed 15 May 2015].

National Statistic Committee of the Republic of Belarus, 2015. Demographic Yearbook of the Republic of Belarus. [online] Available at: <http://www.belstat.gov.by> [Accessed 15 May 2015].

Tatarkin, A.I., 2012. Development of economic space of Russia's regions on the basis of cluster principles. Economic and Social Changes: Facts, Trends, Forecast, 3, pp.28-36. 